\title{
Induced Movement in the Visual Modality: An Overview
}

\author{
A. H. Reinhardt-Rutland \\ University of Ulster, Newtownabbey, Northern Ireland
}

\begin{abstract}
Induced movement, illusory movement in a stationary stimulus resulting from adjoining movement, has received steady experimental investigation over the last 70 years or so. It is observed under different viewing conditions in a wide variety of displays that differ considerably in overall size and in form of inducing and induced stimuli. Explanations have been diverse, some being based on relations within the display and others invoking mediation by other aspects of the observer's perception. Probably, no one explanation can account for all forms of induced movement. Current knowledge about induced movement may have important implications for visual perception of object motion.
\end{abstract}

Induced movement is one of a number of phenomena-including apparent movement, autokinetic movement, and movement aftereffect-in which movement is perceived, although the corresponding distal stimulus is physically stationary. It normally results from physical movement adjoining the stationary stimulus; the induced movement is in the direction opposite that of the adjoining movement. In a typical laboratory demonstration of the phenomenon, induced movement is observed in a small, stationary spot surrounded by a large, moving rectangular frame; the frame and spot are luminous and are viewed in the dark. Familiar naturalistic examples of the phenomenon lie in the perceived drift of the moon and tall buildings in the direction opposite that of clouds in windy conditions. Applied perspectives go beyond the scope of this overview, although Ross (1974) identified induced movement as a possible factor in perception under difficult visual conditions; induced movement in depth might be involved in close following on the road, a part of what is sometimes labeled motorway madness (ReinhardtRutland, 1985).

A major purpose of this review is to summarize empirical findings concerning induced movement (Empirical Findings section). Since early empirical investigation of induced movement by Carr and Hardy (1920), Thelin (1927), and Duncker (1929/1938), there has been a steady trickle of reports showing that induced movement can occur in a wide variety of displays. Among possibly important factors is size of display, which can vary from two small spots (e.g., Carr \& Hardy, 1920) to displays occupying most of the observer's visual field (e.g., Post, 1986).

A second major purpose of this overview is to examine explanations for induced movement (Explanations section). Duncker's (1929/1938) findings have had an important influence here, although many of his suggestions have subsequently been shown to require at least some modification. For example, his theory

I thank J. Morss for reading an earlier version of this article, J. Ravey for translation, and two anonymous referees for helpful suggestions.

Correspondence concerning this article should be addressed to A. H. Reinhardt-Rutland, Room 17J05, Department of Psychology, University of Ulster, Shore Road, Newtownabbey, Co. Antrim, BT37 0QB, Northern Ireland. of frame of reference suggests that movement is assigned in a display according to the configuration of that display. Thus, among other things, a surrounded area is likely to be seen as moving, whereas a surrounding area is likely to be seen as stationary. Subsequently, it has been shown that this principle can sometimes be departed from (e.g., Wagenaar, Frankenhuizen, Vos, \& Flores d'Arcais, 1984). Some subsequent theories, in the spirit of Duncker's, suppose that induced movement can be explained by reference to features of the display itself (e.g., Over \& Lovegrove, 1973). Others suggest that induced movement is mediated by alteration of the observer's perception of space, for example, because of eye movement (e.g., Bruell \& Albee, 1955) or shift of the observer's perceived straight ahead (e.g., Brosgole, 1966).

Since Duncker (1929/1938), it has sometimes been implicit that induced movement is substantial only in cases of nearthreshold motion of the inducing stimulus (e.g., Bassili \& Farber, 1977). Many studies, however, now investigate induced movement with inducing movement well above threshold (e.g., Gogel, 1979; Wallach \& Becklen, 1983). Such points suggest that induced movement, rather than being a phenomenon associated with relatively restricted conditions, may be of general significance in visual perception of object motion. Indeed, it has been suggested that induced movement may be analyzed by essentially the same mechanisms as "real" movement is analyzed by (e.g., Gogel, 1979). I make some comments on this issue in the Induced Movement and General Visual Perception of Object Motion section.

\section{Empirical Findings}

\section{Types of Display}

Induced movement can arise from linear motion with and without overall displacement of the inducing stimulus (Carr \& Hardy, 1920; Duncker, 1929/1938; Over \& Lovegrove, 1973), rotational motion (Duncker, 1929/1938), and motion in depth. The last was first formally indentified by Farne (1970), although it can be inferred from experiments concerned with other issues (Gogel, 1956; Ittelson, 1951). Two-dimensional induced expansion or contraction can also be observed, often in displays giving 
rise to induced movement in depth (Farne, 1970; ReinhardtRutland, 1983c; Wade \& Swanston, 1984). Two other studies have involved what are, on the face, induced expansion or contraction and induced movement in depth (Anstis, Shopland, \& Gregory, 1961; Hershberger, Laughlin, \& Nitschke, 1976). However, in both cases, perceived expansion and contraction were traded off against perceived movement in depth. Induced movement is not normally regarded as involving the trading off of one type of motion against another type in the same stimulus. In cases of true induced movement toward the observer, for example, the induced stimulus may be perceived to undergo induced expansion, rather than compensating contraction (e.g., Farne, 1970).

Linear induced movement is undoubtedly the form that has been given the most attention, particularly when it involves a spot surrounded by a steadily displacing frame. Induced rotation has received relatively little attention since Duncker's (1929/1938) early observations (Day, 1981; Reinhardt-Rutland, 1981). Much the same is true of induced movement in depth (Farne, 1972, 1977; Gogel \& Griffin, 1982; ReinhardtRutland, 1983c), and induced expansion and contraction have apparently received independent investigation in only one study (Wade \& Swanston, 1984).

Normally, the induced and inducing stimuli have at least some degree of shared orientation. This was not true in Wade and Swanston's (1984) study, in which inducing and induced stimuli were orthogonal. Although they were inclined, for this reason, not to categorize their effect as induced movement, it otherwise seems to be comparable to induced movement in general.

A (less than exhaustive) list of factors that have varied across different displays follows:

1. Form of the inducing stimulus. This can vary in size from a spot often the size of the induced stimulus, itself also a spot (e.g., Carr \& Hardy, 1920; Duncker, 1929/1938; Mack, Fisher, \& Fendrich, 1975; Thelin, 1927; Wagenaar et al., 1984), to a pattern filling virtually all the subject's visual field (e.g., Post, 1986; Post \& Heckman, 1986). Variations of the frame stimulus involve filling the frame with pattern (e.g., Bacon, Gordon, \& Schulman, 1982; Wallach \& Becklen, 1983). The shape of the frame is normally rectangular, although circular frames have also been used (e.g., Schulman, 1981; Wallach, 1959). There is no evidence that shape of frame has much effect on induced movement. Certain forms of linear induced movement use a pattern viewed behind a "window": Unlike frame-and-spot induced movement, the inducing movement does not therefore show an overall displacement (e.g., Levi \& Schor, 1984; Nakayama \& Tyler, 1978; Over \& Lovegrove, 1973). Nakayama and Tyler (1978) used two parallel lines oscillating in counterphase, orthogonally to their orientation. Over and Lovegrove (1973) and Levi and Schor (1984) used spatial-frequency gratings drifting in one direction. For induced rotation, the inducing stimulus has often been a patterned annulus surrounding and concentric with the induced stimulus (Day, 1981; Reinhardt-Rutland, 1981). For induced movement in depth, the inducing stimulation has included a surface oscillating in depth (Farne, $1970,1972)$, binocularly generated oscillation in depth of dots (Gogel \& Griffin, 1982), and a rotating spiral (Reinhardt-Rutland, 1983c, 1985). Induced expansion and contraction arose from a grating "zooming in" and "zooming out" within a fixed window (Wade \& Swanston, 1984).

2. Form of the induced stimulus. The induced stimulus is often a spot in studies of linear induced movement (e.g., Brosgole, 1966; Duncker, 1929/1938; Gogel \& Griffin, 1982; Wallach, 1959; Wallach \& Becklen, 1983) and occasionally in studies of induced movement in depth (Gogel \& Griffin, 1982). Other induced stimuli include pairs of lines surrounded by the inducing stimulus (Farne, 1970; Nakayama \& Tyler, 1978) and areas of pattern, such as gratings (e.g., Levi \& Schor, 1984; Over \& Lovegrove, 1973). Induced rotation has used patterned discs (Day, 1981; Reinhardt-Rutland, 1981). Generally, the induced stimulus is smaller than the inducing stimulus, and evidence suggests that this can often influence perception of movement (e.g., Oppenheimer, 1935; van Waters, 1934). The quite popular spotspot induced movement is a case in which induced and inducing stimuli are often matched in size (e.g., Carr \& Hardy, 1920). For induced rotation and an associated aftereffect (Aftereffects and Adaptation of Induced Movement section), the induced stimulus was 10 times larger than the inducing stimulus in Reinhardt-Rutland's (1981) study.

3. Physical motion of the inducing stimulus. In some displays, particularly involving spot and frame, the inducing stimulus starts, moves steadily in one direction, and then stops (e.g., Day, Miller, \& Dickinson, 1979; Duncker, 1929/1938; Rock, Auster, Schiffman, \& Wheeler, 1980; Wagenaar et al., 1984; Wallach, 1959). In other displays, the inducing stimulus has oscillatory movement (e.g., Becklen \& Wallach, 1985; Carr \& Hardy, 1920; Gogel, 1979; Gogel \& Griffin, 1982; Wallach \& Becklen, 1983). Such differences raise the question of whether acceleration of the inducing stimulus may have an effect: It seems likely that induced movement from oscillatory motion can be stronger than induced movement from steady motion (Speed Effects section). In induced movement without overall displacement of the inducing stimulus, the inducing movement can be steady (e.g., Day, 1981; Levi \& Schor, 1984; Over \& Lovegrove, 1973; Reinhardt-Rutland, 1981, 1983c).

4. Physical motion of the induced stimulus. Although the induced stimulus is generally stationary (e.g., Day, Dickinson, \& Forster, 1976; Duncker, 1929/1938; Wagenaar et al., 1984; Wallach, 1959), except for purposes of nulling (Response Measures section, Item 3), it may have a physical motion imposed on it, a motion that is orthogonal to any induced movement that it may possess. In such displays, the subject is often required to track the motion of the induced stimulus (e.g., Gogel, 1979; Gogel \& Griffin, 1982; Wallach \& Becklen, 1983). Tracking has implications for response measures (Response Measures section) and may affect induced movernent (Speed Effects section).

5. Amount of competing visual information irrelevant to the stimulus display. Since Duncker's (1929/1938) comment that induced movement may be inhibited if the observer can perceive the room in which the experiment is taking place, it has been clear that superfluous visual information generally needs to be reduced to a minimum. It might, for example, affect threshold measurements of induced movement. Little is known, however, about how important competing visual information might be in any given stimulus configuration, and determining the freedom from such information in stimulus configurations described in reports is not always easy. 


\section{Possible Distinction Between Induced Movement With and Without Overall Displacement of the Inducing Stimulus}

Reasonable evidence now exists for making a broad distinction between induced movement involving overall displacement of the inducing stimulus (generally the frame-and-spot form) and induced movement not involving overall displacement of the inducing stimulus; the second category includes induced rotation and most forms of induced movement in depth, although in view of the relative lack of attention directed to the latter, their precise relation to the more familiar, linear forms has not been fully explored. Spot-spot induced movement does not fall readily into either category, and in the absence of information relating to the distinctions made below, I exclude it from consideration here. Also, if inducing movement extends beyond the visual field in the direction of movement (e.g., Post, 1986), a fixed or displacing frame cannot be observed, and the categorization is not appropriate.

The first distinction lies in dichoptic effects, greater for induced movement with overall displacement of the inducing stimulus (80+\% or so: Bassili \& Farber, 1977; Day \& Dickinson, 1977) than for induced movement with no overall displacement of the inducing stimulus (25\% or so: Day \& Dickinson, 1977; Levi \& Schor, 1984; Swanston \& Wade, 1983). Broadly consistent with the latter is a $40 \%$ dichoptic effect for induced rotation (Wade \& Day, personal communication, June 11, 1984) and $25 \%$ interocular transfer of aftereffect of induced rotation (Reinhardt-Rutland, 1983b; Aftereffects and Adaptation of Induced Movement section).

Second, surrounding of the induced stimulus by the inducing stimulus may not always be required for induced movement involving overall displacement of the inducing stimulus (Oppenheimer, 1935; Wagenaar et al., 1984); Day et al. (1979) found that surrounding of the induced stimulus did not necessarily lead to induced movement. With regard to induced movement without overall displacement of the inducing stimulus, surrounding of the induced stimulus by the inducing stimulus is important for induced rotation (Day, 1981; Reinhardt-Rutland, 1981) and induced movement in depth (Reinhardt-Rutland, 1983c); investigations of linear induced movement without overall displacement of the inducing stimulus seem invariably to have involved an inducing stimulus surrounding the induced stimulus (Day \& Dickinson, 1977; Levi \& Schor, 1984; Nakayama \& Tyler, 1978; Over \& Lovegrove, 1973; Tynan \& Sekuler, 1975).

Third, the amount of induced movement is less for displays involving an inducing stimulus that shows overall displacement, compared with displays involving an inducing stimulus that does not, in displays that otherwise appear matched (Day \& Dickinson, 1977).

Finally, there is evidence that linear induced movement without overall displacement of the inducing stimulus is somewhat dependent on a match in color between inducing and induced stimuli, but this appears much less true for linear induced movement involving overall displacement of the inducing stimulus (Day \& Dickinson, 1977; Over \& Lovegrove, 1973).

Day and Dickinson (1977) argued that perceived motion in their displays not involving overall displacement of the moving stimulus may have been artifactual, being dependent on the changing phase relation between inducing and induced stimuli. Further, they suggested that dichoptic effects in these displays were artificially low because of difficulty in obtaining satisfactory fusion. These points, however, do not seem to have been subsequently developed.

\section{Response Measures}

Unlike research with movement aftereffects, in which response measures are often confined to duration of effect, response measures for induced movement are diverse. This partly reflects the variety of displays used for induced movement: One important distinction lies again in cases of inducing stimuli with and without overall displacement. The former are normally constrained to move within limits dictated by the observer's visual field, which is not a problem with the latter because inducing stimulation is within a particular area and, therefore, it can be continuous in one direction. The only way to get continuing inducing movement in the former is to use an oscillating inducing stimulus. Among response measures for assessing induced movement have been the following:

1. Qualitative responses to indicate the presence or absence of induced movement and, if present, its direction (e.g., Day et al., 1979; Duncker, 1929/1938; Farne, 1970, 1972; Mack et al., 1975; Wagenaar et al., 1984; Wallach, 1959). These are useful in cases in which effects are small or short-lived.

2. Tracking induced movement by means of a hand control operating an unseen pointer (e.g., Brosgole, 1968; Day et al., 1976).

3. Nulling induced movement with real movement (e.g., Day, 1981; Levi \& Schor, 1984). This assumes a form of induced movement that is reasonably stable over the short periods required for making adjustments of the induced stimulus.

4. Setting a comparison stimulus to the perceived speed of the induced stimulus (Post, 1986).

5. Pointing to either end of the perceived path of the stimulus in which induced movement is to be observed (e.g., Bridgeman, Kirch, \& Sperling, 1981; Gogel, 1979).

6. Timing induced movement during a fixed period of operation of the inducing stimulus (e.g., Reinhardt-Rutland, 1981, $1983 \mathrm{c}$ ). This assumes a form of induced movement that is likely to be intermittent, is subject to decay, or both.

7. Indicating the angle of the path of the induced stimulus. This technique involves the induced stimulus undergoing physical movement perpendicular to the putative induced movement. Suppose the physical movement is vertical and the putative induced movement is horizontal. Vector addition of the two will give a path of the induced movement at some angle to the vertical (e.g., Gogel, 1979; Gogel \& Griffin, 1982; Wallach, Bacon, \& Schulman, 1978). A variant of this may yield an elliptical path, the width of which is to be judged (e.g., Becklen \& Wallach, 1985; Wallach \& Becklen, 1983).

8. Assessing lower and upper thresholds for detection of induced movement by adjusting the amplitude of an oscillatory inducing movement (Nakayama \& Tyler, 1978).

Care may be needed in interpretation and comparison of different measures. For example, in pointing tasks involving judgments of altered displacement, it is implicit that induced 
movement necessarily affects displacement, which may not be in accord with subjects' perceptions (Bacon et al., 1982; Bridgeman et al., 1981). Tracking induced movement may suppose that a manual task can match perceived velocity of the induced stimulus (Day et al., 1976). Despite such points, the comparison of different response measures has not been a major research concern. Gogel (1979), however, reported comparable results from tasks involving pointing to the perceived extent of displacement of an induced stimulus and tasks assessing the angle of the perceived path of an induced stimulus with physical movement orthogonal to induced movement. Perhaps, as may be true for movement aftereffect (e.g., Pantle, 1974), different response measures are of broadly equivalent value.

\section{Speed Effects}

At near-threshold movements of the inducing stimulus in many frame-and-spot studies, movement is assigned almost invariably to the spot (e.g., Duncker, 1929/1938). Above-threshold movements of the inducing stimulus tend to produce less induced movement (Brosgole, 1968; Duncker, 1929/1938; Rock, 1983; Rock et al., 1980). This applies to fixation conditions in which the inducing stimulus moves steadily for a short period in one direction. With an oscillating inducing stimulus, sometimes with tracking eye movements on a moving induced stimulus, the amount of induced movement has not been reported to diminish by having speed of the inducing stimulus well above threshold (Gogel, 1979). It is likely that a moving spot always shows more induced movement than does a fixated spot (Bacon et al., 1982; Bridgeman \& Klassen, 1983). Induced movement may never disappear, no matter what the speed of an oscillating inducing stimulus (Becklen \& Wallach, 1985). Wallach and Becklen (1983) and Becklen and Wallach (1985) showed that at high speeds (inducing movement in their displays was up to an average of $31.7^{\circ}$ of visual angle per second), the effectiveness of the inducing stimulus in producing inducing movement becomes diminished. The results were not due to retinal image blur of the inducing stimulus.

The picture is different for other forms of induced movement, at least during fixation. No evidence associates the best linear induced movement without overall displacement of the inducing stimulus and induced rotation with near-threshold movement of the inducing stimulus (Day, 1981; Levi \& Schor, 1984; Nakayama \& Tyler, 1978). Nakayama and Tyler (1978) and Levi and Schor (1984) both found an upper threshold of the inducing stimulus speed, above which induced movement was reduced. Possibly, the amount of induced movement can be elevated by using an oscillating inducing movement, tracking the induced stimulus, or both (see, e.g., Wallach \& Becklen, 1983, Experiment 4), as can induced movement with overall displacement of the inducing stimulus. Although Nakayama and Tyler's (1978) inducing stimulus oscillated, it cannot readily be compared in this respect with other cases.

Finally, if the inducing stimulus extends beyond the periphery of the visual field, the reduction of induced movement seems to occur at particularly high speeds during fixation of a stationary induced stimulus: Induced movement shows a steady increase at least up to a speed of $60^{\circ}$ per second of the inducing stimulus (Post, 1986; see also Post \& Heckman, 1986). It is pos- sible that this form of induced movement may be unusual, because the dimensions of Post's inducing stimulus and the viewing conditions suggest that visually induced movement of the self might be strong (see Alteration of the Observer's Perception of Space section).

\section{Adjacency, Spatial Frequency, and Their Interaction With Speed}

Gogel and Koslow (1972) and Gogel and MacCracken (1979) proposed that induced movement is affected by the adjacency principle. This suggests that induced movement is most effectively elicited when induced and inducing stimuli are as close as possible in all three dimensions of space. The adjacency principle may apply in other perceptual phenomena, such as the Ponzo illusion (Gogel, 1975) and the rod-and-frame effect (Gogel \& Newton, 1975).

Evidence concerning frame-and-spot induced movement (Schulman, 1981) suggests that the adjacency of an inducing stimulus may be modified by its speed: In essence, Schulman (1981) showed that the speed of a smaller inducing stimulus needed to be lower than the speed of a larger inducing stimulus for them to be equally effective given that they were in the same plane. This finding seems related to the perception of speed in moving patterns of different sizes: A smaller pattern is required to move at a slower physical speed than a larger pattern, for them to have phenomenally equal speeds (Brown, 1931; Diener, Wist, Dichgans, \& Brandt, 1976). It also may be in accord with a finding involving linear induced movement without overall displacement of the inducing stimulus: Effectiveness of an inducing stimulus is affected by the inducing pattern's spatial frequency and speed, such that a high-frequency inducing pattern requires a lower speed to be effective than does a low-frequency inducing pattern (Levi \& Schor, 1984). A small inducing frame in Schulman's (1981) experiment would, presumably, have had a higher frequency spectrum than a large inducing frame. The above may be important in interpreting evidence from induced movement involving two moving frames (Duncker's, 1929/ 1938, Theory section and Alteration of the Observer's Perception of Space section).

Levi and Schor (1984) plotted "tuning curves" for spatial frequency of inducing stimuli, for fixed values of frequency of induced stimuli to try to determine how far inducing and induced stimuli should be matched for spatial frequency to get good induced movement. Temporal frequency of inducing stimuli was fixed, so that high-frequency inducing stimuli moved faster than low-frequency inducing stimuli. The tuning curves were broad, and the optimum inducing spatial frequency often did not correspond to the spatial frequency of the induced stimulus. Broadly, spatial frequency does not seem to be a major determinant of induced movement, provided that temporal frequency rather than speed is the determining factor of the motion of the inducing movement.

A proviso to the above points may lie in the relative ineffectiveness of particularly small inducing frame stimuli (Day et al., 1979), possibly no matter what their speed. Furthermore, there is no evidence of speed effects in some experiments (e.g., Gogel, 1979; Speed Effects section); the reason for the discrepency is not obvious. 


\section{Eye Movements}

A number of workers have investigated the possible involvement of eye movements in induced movement. The results have been negative (Bassili \& Farber, 1977; Brosgole, 1966; Brosgole, Cristal, \& Carpenter, 1968; Levi \& Schor, 1984; Mack, 1970; Schulman, 1979). Techniques used have ranged from direct measurement of eye movements (e.g., Brosgole, 1966; Levi \& Schor, 1984) to a technique involving distinctive distal stimulation causing proximal stimulation at the blind spot: The distinctive stimulation would be perceived if the eye moved (Bassili \& Farber, 1977).

In addition, a number of researchers have used displays in which movement is centrifugal or centripetal, so that systematic eye movements are, presumably, not possible (Farne, 1972; Gogel, 1977; Gogel \& Griffin, 1982; Nakayama \& Tyler, 1978; Reinhardt-Rutland, 1983c; Wade \& Swanston, 1984).

With regard to induced rotation, a possibility that torsional eye movements could contribute to the effect seems untenable. An examination of Day's (1981) results, using a uniformly patterned inducing stimulus, showed that there could be a perceived rotation of the induced stimulus of about $15^{\circ}$ during a 6$s$ rotation of the inducing stimulus: The maximum eye torsion obtained by Hughes (1972) from a uniformly patterned rotating disc was about $1^{\circ}$.

\section{Aftereffects and Adaptation of Induced Movement}

Viewing induced rotation for $1 \mathrm{~min}$ or so may lead to a negative aftereffect in the induced stimulus. This arises both from motion adaptation in the inducing stimulus and from the previously observed induced movement itself(Anstis \& ReinhardtRutland, 1976). The former probably explains an old finding (Wohlgemuth, 1911, Experiment 21) that motion adaptation can give rise to movement aftereffect in an adjoining area that has been without pattern during adaptation. These results counter the common belief that image displacement is crucial for the movement aftereffect (Anstis \& Gregory, 1965; Moulden, 1975; Sekuler \& Ganz, 1963). Incidentally, Wohlgemuth's display appears superficially similar to other displays in which, however, an aftereffect is reported in the same direction as the motion-adapted area (Bonnet \& Pouthas, 1972; Smith \& Over, 1979; Weisstein, Maguire, \& Berbaum, 1977). Crucial differences between the latter and Wohlgemuth's display probably lie in the size of the nonadapted area and the degree of good continuity (Kohler, 1947) across the motion-adapted pattern.

Peripheral location of inducing stimulus relative to induced stimulus is important in aftereffect of induced rotation (Reinhardt-Rutland, 1981) and aftereffect of induced movement in depth (Reinhardt-Rutland, 1984). After tracking linear movement of a pattern, surrounded by a stationary pattern, a negative aftereffect can be observed in the tracked pattern after it stops (Morgan, Ward, \& Brussel, 1976). Because tracking eye movements-and other eye movements for that matter-do not contribute to movement aftereffects (Anstis \& Gregory, 1965; Moulden, 1975; Sekuler \& Ganz, 1963), Morgan et al. concluded that the effect was induced by the surrounding pattern; during tracking, the latter would become adapted because of image displacement.
Finally, Wallach et al. (1978) reported an adaptation effect following several minutes of viewing induced movement. They observed linear induced movement in a spot with vertical physical movement and horizontal induced movement: They measured induced movement by the angle of the spot to the vertical. This angle became nearer the vertical after the prolonged viewing. Adaptation could be viewed as resolution of stimulus conflict, of a sort that seems to occur in adaptation to displaced vision, for example (Harris, 1980). Wallach et al. (1978) argued against a possibility that adaptation arose because of reduced effectiveness of the inducing stimulus as a result of its sensory adaptation. However, the inducing stimulus extended well into peripheral vision, in which sensory-movement adaptation can be severe (Cohen, 1965; Hunzelman \& Spillman, 1984; see also Taylor, 1963).

\section{Induced Movement and Other Illusions}

Induced movement can be observed when the inducing stimulus is displaced to give apparent or stroboscopic motion (Bridgeman et al., 1981; Bridgeman \& Klassen, 1983; Duncker, 1929/1938; Farne, 1972). Bridgeman and Klassen argued that such induced displacement is dependent on a lateral shift in the observer's perceived space, resulting from displacement of the induced stimulus (see Alteration of the Observer's Perception of Space section). This could not, however, apply to one of Farne's (1972) experiments. This used an inducing stimulus of two concentric circles of different sizes that appeared, when presented sequentially, to move toward or away from the observer. Hence, the inducing stimulus could not lead to a lateral shift in the observer's perceived space. The induced stimulus was a smaller concentric circle that was perceived to move in counterphase with this inducing movement. The resulting effect might not have been a simple induced movement, because the display had a strong affinity with certain size-contrast illusions in static stimuli (Coren \& Girgus, 1978; Robinson, 1972). These may have affected perception in the depth domain.

In frame-and-spot induced movement, the frame can be removed after induced movement has commenced, and the spot, still physically stationary, will continue to show perceived movement (Day et al., 1976). Without reference information, people often perceive a physically stationary spot to move randomly (autokinetic movement, e.g., Pola \& Matin, 1977; Royce, Carran, Aftanas, Lehman, \& Blumenthal, 1966). In their experiments, Day et al. (1976), however, invoked lack of information indicating that the spot had stopped. Post (1986) reported a more complex effect in which the induced stimulus was seen to continue to move in the same direction immediately after removal of the inducing stimulus and then in the opposite direction. He attributed this to optokinetic after nystagmus (Felt and Canceled Eye Movements section).

\section{Explanations}

As shown in the Empirical Findings section, induced movement is observed in a wide range of displays, and this has undoubtedly led to some divergence in suggested explanations for induced movement. An explanation originally identified in 
connection with one type of display has often been found to have limited applicability in other types of display.

\section{Duncker's (1929/1938) Theory}

Duncker (1929/1938) investigated linear induced movement in frame-and-spot and spot-spot form, induced rotation, and induced movement of the self. The last has subsequently received considerable investigation as an unrelated phenomenon, being labeled vection (Dichgans \& Brandt, 1978; Henn, Cohen, \& Young, 1980).

Duncker's (1929/1938) frame-of-reference theory is an $o b$ ject-relative theory (Wallach, 1959) in that it views induced movement as deriving from the configuration of the display. It supposes that small areas and relatively central areas are predisposed to be seen as moving. Although probably generally true, neither principle is absolute (Types of Display section and Possible Distinction Between Induced Movement With and Without Overall Displacement of the Inducing Stimulus section). Included in the theory is the concept of separation of systems, according to which, if there are more than two components in the display, there can be more than one frame of reference. Thus, an inducing stimulus can act as the frame of reference for an induced stimulus it surrounds and be the sole determinant of its perceived movement, even if the inducing stimulus is surrounded by another inducing stimulus; the latter should lead to induced movement in the former. Qualified support for this suggestion came from Wallach (1959). However, careful interpretation is needed (Adjacency, Spatial Frequency, and Their Interaction With Speed section).

Another of Duncker's (1929/1938) principles is that a fixated stimulus is more likely to be seen as moving than is a nonfixated spot. The application is mainly to spot-spot induced movement. There is little conclusive evidence for the principle: Whereas Thelin (1927) and van Waters (1934) found results consistent with Duncker's suggestion, Carr and Hardy (1920) and Wagenaar et al. (1984) found inconclusive results, and Mack et al. (1975) found the reverse effect.

\section{Alteration of the Observer's Perception of Space}

Brosgole (1966, 1968) challenged both Duncker's (1929/ 1938) frame-of-reference theory and the subsumed separationof-systems concept. He suggested that the observer's perceived straight ahead, determined by the center of the inducing stimulus, shifted with the inducing stimulus (Roelofs, 1935). A physically stationary spot is therefore seen to move as a result of the observer's altered perception of space. Such an interpretation is labeled subject relative (Shaffer \& Wallach, 1966). Since Roelofs's effect depends on the degree of eccentricity of the stimulus eliciting it, a test for Duncker's (1929/1938) and Brosgole's $(1966,1968)$ theories seems to lie in the effect on induced movement when the induced stimulus is surrounded by one moving stimulus, which is in turn surrounded by another moving stimulus. Duncker's separation-of-systems principle suggests that induced movement is determined by the inner moving stimulus. Brosgole $(1966,1968)$ found that perception of the doubly surrounded induced stimulus in his experiments depended on the outer moving stimulus. Bassili and Farber (1977) also failed to find evidence for separation of systems. However, as indicated in the Adjacency, Spatial Frequency, and Their Interaction With Speed section, the interpretation of such evidence requires care, because it may be affected by the speeds of the moving stimuli.

Other evidence concerns Duncker's (1929/1938) principle of surroundedness or enclosure, according to which induced movement should be assigned to a surrounded object. Brosgole's $(1966,1968)$ theory does not require that the induced stimulus be surrounded by the inducing stimulus. Enclosure is not always necessary for induced movement when the inducing stimulus undergoes overall displacement (Oppenheimer, 1935; Wagenaar et al., 1984; Possible Distinction Between Induced Movement With and Without Overall Displacement of the Inducing Stimulus section).

Subsequently, major problems have been identified with Brosgole's $(1966,1968)$ theory. First, induced movement can occur with an inducing stimulus with no overall direction of motion (Gogel, 1977; Gogel \& Griffin, 1982; Nakayama \& Tyler, 1978; Reinhardt-Rutland, 1983c; Wade \& Swanston, 1984), so that no shift in the observer's straight ahead is possible. Second, Bacon, Gordon, and Schulman (1982) showed that a shift in the perceived straight ahead occurs only if the inducing stimulus undergoes overall displacement. Roelofs's (1935) effect was also reported to probably be weak in a study involving high-speed oscillation of the inducing movement and tracking of a moving induced stimulus (Wallach \& Becklen, 1983) and did not correspond to the time course of induced movement in a display filling most of the subject's visual field (Post \& Heckman, 1986).

More recently, authors have expressed doubts about whether Roelofs's (1935) effect can have any role in explaining induced movement. Mack, Heuer, Fendrich, Vilardi, and Chambers (1985) argued, first, that Roelofs's effect is often found to be incomplete (Bacon et al., 1982; Howard, 1966; Sugarman \& Cohen, 1968), whereas movement in an induced movement display may be entirely attributed to the induced stimulus. More crucially, they argued that Roelofs's effect is not truly perceptual but, rather, is judgmental, in a way suggested by Harris (1974) for adaptation to displaced vision. This implies that Roelofs's effect is not affected by and does not affect other aspects of perception. Roelofs's effect, if truly perceptual, should be accompanied by eye movement, head movement, body movement, or any combination of the three. No evidence suggests that this occurs for eyes (Eye Movements section and Felt and Canceled Eye Movements section) or for head and body, in which case visually induced movement of the self (vection) might be predicted. Roelofs's effect does, however, seem to require stimulation different from that necessary for vection: The stimulus normally used gives good information that it has been displaced, but a uniform pattern is usual for vection (Dichgans \& Brandt, 1978).

Vection can occur during perception of induced rotation (Anstis \& Reinhardt-Rutland, 1976) and linear induced movement (Rock et al., 1980). In Rock et al.'s study, however, the form of induced movement was unusual, because it was perceived to be locked with the observer's perceived self-movement: The phenomenal experience of induced movement is that it appears normally to be independent of the observer. Inciden- 
tally, this point might contribute to Post's (1986) unusual results concerning speed of inducing stimulus (Speed Effects section). Vection probably involves mechanisms separate from those leading to induced rotation, because aftereffects of induced rotation are always negative (Reinhardt-Rutland, 1981), whereas aftereffects of roll vection are frequently positive (Held, Dichgans, \& Bauer, 1975).

In contrast to Mack et al. (1985), Bacon et al. (1982) and Bridgeman and Klassen (1983) argued that there can be a component of the Roelofs (1935) type in induced movement, along with a configurational component based on motion within the display. An important feature of such a model is that it could supply a reason for the differences in a number of characteristics of induced movement with and without overall displacement of the inducing movement, noted in the Possible Distinction Between Induced Movement With and Without Overall Displacement of the Inducing Stimulus section. It would explain the difference in size of effects (Day \& Dickinson, 1977). Also, the relatively large dichoptic effects in induced movement with overall displacement of the inducing movement (Bassili \& Farber, 1977; Day \& Dickinson, 1977) might be explained if the observer's altered perception of space is a whole-body effect, not restricted to the eye of stimulation. The failure to find a strong effect of enclosure for induced movement involving overall displacement of the inducing stimulus (Oppenheimer, 1935; Wagenaar et al., 1984) could be explained by the fact that the observer's alteration of perceived space presumably affects the whole visual field so that location of the inducing stimulus is unimportant. Finally, the relative lack of color selectivity for induced movement with overall displacement of the inducing stimulus (Day \& Dickinson, 1977) might plausibly be due to the fact that alteration of perceived space is independent of the color of the stimulus causing that alteration. These discrepancies ultimately might be explained by other subject-relative mechanisms, but none have been identified yet. For example, explanation in terms of canceled eye movements does not seem to predict any of the qualitative discrepencies (Felt and Canceled Eye Movements section).

If Roelofs's (1935) effect has a possible role in linear induced movement, one might wonder whether the analagous rod-andframe effect (Goodenough, Oltman, Sigman, \& Cox, 1981; Witkin, Dyk, Faterson, Goodenough, \& Karp, 1962/1974) contributes to induced rotation. The rod-and-frame effect is an illusory tilt of the observer produced by a visually presented tilted stimulus; the stimulus, perhaps a room or rectangular frame, normally has strong information concerning its angular displacement. Little evidence supports a role for the rod-andframe effect in induced rotation. Day's (1981) results suggest a perceived rotation of about $15^{\circ}$ in the induced stimulus during rotation for $6 \mathrm{~s}$ of a uniformly patterned inducing stimulus (Eye Movements section). Hughes (1972) found that a uniformly patterned stimulus produced a maximum perceived tilt of observer of about $1^{\circ}$. Furthermore, a nonuniform arrangement of the pattern in the inducing stimulus, which should increase any rod-and-frame effect, did not significantly affect the duration of aftereffect (Reinhardt-Rutland, 1983a).

\section{Felt and Canceled Eye Movements}

Although eye movements have not been reported during induced movement (Eye Movements section), some authors have suggested that induced movement may be explained by felt eye movements (McConkie \& Farber, 1979; Rock et al., 1980). Mack et al. (1985) supposed that felt eye movements should affect saccadic eye movements made in reaction to an unseen auditory stimulus, subsequent to viewing an induced movement display. They could find no evidence for this and therefore concluded that felt eye movements were not involved in induced movement.

Another suggestion is that induced movement represents an interaction between two visual tracking systems, one concerned with tracking the stationary environment during observer movement and one concerned with tracking a moving object (Bruell \& Albee, 1955; Post, 1986; Post \& Heckman, 1986; Post \& Leibowitz, 1985; Post, Schupert, \& Leibowitz, 1984). The former is supposed to be involuntary and reflexive and is concerned with maintaining a reasonably steady retinal image of the stationary environment during observer movement; it is associated with optokinetic nystagmus. The latter is supposed to be under voluntary control. The latter but not the former may give rise to the perception of object motion. During linear frame-and-spot induced movement, observers, in the absence of instructions to fixate, pursue the inducing stimulus as a result of the first type of visual tracking system (Post et al., 1984). When the observer fixates on the static induced stimulus, the second type of visual tracking system, which gives rise to perception of movement of the object, has to be used.

Evidence for this theory comes from the observation that after removing inducing stimulation, the induced stimulus can undergo two phases of illusory movement (Post, 1986; Induced Movement and Other Illusions section): These could correspond to the two phases of optokinetic after nystagmus (e.g., Aschan \& Bergstedt, 1955; Collewijn, 1969), which can also occur after removal of a large moving pattern. This possible relation is complicated, however, by the fact that an illusory selfmovement can occur under similar conditions if vection is observed prior to removal of the moving stimulus: The illusory self-movement also has two phases (Dichgans \& Brandt, 1978). I have already noted the possibility that Post's display may elicit an unusual form of induced movement associated with circular vection (Alteration of the Observer's Perception of Space section).

As Post (1986) acknowledged, his explanation cannot be applied to cases of induced movement in which there is no overall direction of movement of the inducing stimulus (e.g., Gogel, 1977; Gogel \& Griffin, 1982; Nakayama \& Tyler, 1978). Furthermore, it cannot explain the differences often found between induced movement with and without overall displacement of the inducing stimulus (Possible Distinction Between Induced Movement With and Without Overall Displacement of the Inducing Stimulus section), because linear induced movement with overall displacement of the inducing stimulus would presumably be treated in qualitatively the same way as linear induced movement without overall displacement of the inducing stimulus.

One general point concerning any explanation in terms of eye movements, whether real or virtual, is that it must suppose that eye movements are adequately registered by the visual system. This may be particularly problematic at near-threshold movement of the inducing stimulus, because evidence suggests 
that tracking eye movements are seriously underregistered (e.g., Festinger \& Easton, 1974; Festinger, Sedgwick, \& Holtzman, 1976; Stoper, 1973; Westheimer \& McKee, 1973).

\section{Induced Movement and "Intelligent" Perception}

Rock (1983) argued that perception is essentially intelligent, much like thought. Such views have a long history (Ames, 1951; Gregory, 1970; Helmholtz, 1925/1967; Oatley, 1978), although they have been criticized for being of dubious general applicability to the problems of perception (e.g., Gibson, 1966, 1979; Morgan, 1984). Rock (1983) interpreted induced movement in inferential terms. When induced movement in the traditional frame-and-spot display is observed with below-threshold motion of the inducing stimulus, he suggested, the spot is perceived to move perhaps because of intelligent inbuilt principles or perhaps because previous experience leads observers to expect that small or relatively central areas or both normally move, whereas large or relatively peripheral areas or both are normally stationary (see the following sections: Types of Display, Possible Distinction Between Induced Movement With and Without Overall Displacement of the Inducing Stimulus, and Duncker's, 1929/1938, Theory). When frame-and-spot induced movement is observed with above-threshold motion of the inducing stimulus, the motion perceived in the display does not exceed the sum of the motions in the display (Rock et al., 1980). Rock suggested that the observer experiences felt eye movements tracking the spot. As noted in the Felt and Canceled Eye Movements section, such a suggestion has little experimental support.

Most of the above points have been suggested in other contexts: If other theories are available, inferential explanations can have difficulty making distinct predictions. Their support often comes from situations in which no other theory is obviously applicable. Rock (1983) suggested that an appeal to higher perceptual processes should not be made if a lower level of explanation is available. Thus, he accepted the prevailing view that movement aftereffects can be explained by reference to movement-sensitive neural mechanisms. Because observation of induced movement can lead to aftereffects (e.g., Anstis \& Reinhardt-Rutland, 1976; Aftereffects and Adaptation of Induced Movement section), it seems inconsistent to suppose that induced movement is to be explained exclusively in inferential terms.

An appeal to inferential processes may be appropriate in some forms of induced movement. Farne (1977) described a form of induced movement in depth arising from brightness changes. He exploited the fact that bright surfaces tend to be seen as closer than dim ones (Ittelson \& Kilpatrick, 1951). A static disc of constant luminance was seen against a background of changing luminance, which thus was seen as moving in depth and inducing movement in depth of the disc. In another example, a picture of a lighthouse was moved toward a stationary picture of a ship and caused induced movement of the ship (Krolik, 1935). Expected direction of movement might also be important (Jensen, 1960). The induced movement in such cases could have been based on inference if, as seems possible, no other aspects of the display caused a predisposition to see induced movement.

\section{Sensory and Neural Processes}

Studies of induced movement without overall displacement of the inducing stimulus (Levi \& Schor, 1984; Nakayama \& Tyler, 1978; Over \& Lovegrove, 1973; Tynan \& Sekuler, 1975) have tended to be linked with a number of displays in which perception of a moving area is affected by movement in an adjoining area (Holmgren, 1974; Loomis \& Nakayama, 1973; Tynan \& Sekuler, 1975; Walker \& Powell, 1974). This is sometimes labeled simultaneous motion contrast. An example is seen in the following (Loomis \& Nakayama, 1973): Two spots, A and B, moving with shared physical speed and direction, were surrounded by other spots, also moving in the same direction but with different physical speeds. Those surrounding A were physically slower than those surrounding $B$. The perception was that $A$ appeared to move faster than $B$, despite the lack of alteration of relative displacement between them. Walker and Powell (1974) reported low dichoptic effects in their experiments, broadly consistent with induced movement without overall displacement of the inducing stimulus (Possible Distinction Between Induced Movement With and Without Overall Displacement of the Inducing Stimulus section).

Simultaneous motion contrast effects are often interpreted in terms of lateral inhibition in motion detectors, by which the response of a given motion-sensitive cell to movement in its receptive field is affected by the presence of movement in an inhibitory surround. This is a development much analogous with that concerning brightness contrast (Cornsweet, 1970; Ratliff, 1965). Evidence for motion-sensitive cells with inhibitory surrounds has been available for some time (e.g., Barlow \& Levick, 1965 , in the rabbit retina; Sterling \& Wickelgren, 1969, in the cat superior colliculus). Subsequently, there have been copious reports that many movement-sensitive neurons show particular responses to relative rather than absolute movement (e.g., Bridgeman, 1972; Burns, Gassanov, \& Webb, 1972; Frost \& Nakayama, 1983; Hammond \& MacKay, 1977, 1981; Mandl, 1970, 1974; Rizzolatti \& Camarda, 1975, 1977; Rizzolatti, Camarda, Grupp, \& Pisa, 1974). In a recent review of psychophysical and physiological evidence, Regan (1986) described a number of types of relative movement that may be analyzed by hardwired neural mechanisms.

Subsequent support for invoking neural processes comes from the identification of aftereffects of induced movement (Aftereffects and Adaptation of Induced Movement section) on the basis that movement aftereffects have been shown to have a likely origin in movement-sensitive neurons (Barlow \& Hill, 1963; Srinivason \& Dvorak, 1979; Vautin \& Berkley, 1977). This is in line with ratio models of neural response (Mather, 1980; Sutherland, 1961). Other aftereffects have been explained in a similar way (e.g., Frisby, 1979).

Evidence from induced movement and aftereffects is consistent with known neural functioning. For example, the importance of the inducing stimulus's being peripheral to the induced stimulus in aftereffects of induced movement (Reinhardt-Rutland, 1981, 1984) might be related to the relative proportions of neurons with different characteristics across the retina (Cleland \& Levick, 1974; Fukuda \& Stone, 1974; Hoffman, 1973; Hoffmann, Stone, \& Sherman, 1972; Leventhal, 1982): Neurons with sustained response (sometimes labeled $X$ cells) are 
more characteristic of the central retina, and neurons with transient response (sometimes labeled $Y$ cells) are more characteristic of the peripheral retina. This may be reflected in different patterns of innervation at the lateral geniculate (Friedlander, Lin, Stanford, \& Sherman, 1981; Sherman, 1985). Distinctions in velocity sensitivity of neurons with eccentricity occur in the cortex (Orban, Duysens, \& van der Glas, 1980; Orban \& Kennedy, 1981; Orban, Kennedy, \& Maes, 1981), with those responding to the periphery being more selective for high velocities than those responsive to the center of vision. This is no doubt reflected also in human motion thresholds (McColgin, 1960).

There is good evidence for believing that receptive fields and inhibitory surrounds for motion-detection mechanisms increase in size with eccentricity in the visual field. Richards (1971) suggested that some inhibitory surrounds in the periphery may extend to as much as $90^{\circ}$ or so, on the basis of a comparison between psychophysical data from movement aftereffects and physiological data (Barlow, Hill, \& Levick, 1964; Humphrey, 1968; Sprague, Marchiafava, \& Rizzolatti, 1968). This is consistent with the observation of an aftereffect of induced movement with a large gap between inducing and induced stimuli (Reinhardt-Rutland, 1983b) and suggests that such neurons may be involved in frame-and-spot induced movement, in which induced and inducing stimuli are often well separated in space.

The findings concerning the variation of velocity sensitivity and receptive field size with eccentricity are also consistent with the variation of effectiveness of inducing stimuli according to size and speed (Schulman, 1981) and can be related to spatialfrequency findings (Levi \& Schor, 1984). A low-spatial-frequency grating occupies a larger distance per cycle than a highfrequency grating, which suggests that the former tends to stimulate neurons that have large receptive fields and are sensitive to high velocity (see Adjacency, Spatial Frequency, and Their Interaction With Speed section).

A more speculative suggestion might contribute to explanation of induced movement with orthogonal induced and inducing stimuli (Wade \& Swanston, 1984; Types of Display section). Such stimuli should stimulate separate movement-sensitive neural populations. However, global mechanisms could be invoked. This is an extension of proposals based on aftereffect evidence. Cavanagh and Favreau (1980) showed that movement aftereffects can be observed when adaptation and test stimuli are mirror-image logarithmic spirals. Each part of one spiral is orthogonal to the corresponding part of the other spiral, so that known motion-sensitive neurons would not be stimulated. The authors inferred a global mechanism, which is not dependent on local stimulation, for responding to rotation. Global mechanisms have been invoked to explain phantom motion aftereffects from spirals (Hershenson, 1984; Aftereffects and Adaptation of Induced Movement section). They can also be inferred from experiments demonstrating separable motion in depth and expansion and contraction aftereffects from the same stimulation (Beverley \& Regan, 1979).

Wagenaar et al. (1984) suggested that induced movement, at least at near-threshold motion of the inducing stimulus, can be entirely explained in terms of low-level sensory processing. Although it is worthwhile to seek the lowest level of explanation, it must be in accordance with empirical findings. An appeal to currently known sensory processes seems unlikely to cover, for example, induced movement in depth described by Farne (1977; Induced Movement and "Intelligent" Perception section), in which an appeal to inference seems appropriate. Also, aftereffect of induced rotation is characterized by small interocular transfer (Reinhardt-Rutland, 1983b), which may be consistent only with induced movement without overall displacement of the inducing stimulus (Adjacency, Spatial Frequency, and Their Interaction With Speed section). Finally, because induced displacement (Bridgeman et al., 1981; Duncker, 1929/1938; Farne, 1972; Induced Movement and Other Illusions section) has involved large shifts of the inducing stimulus, it may not stimulate known motion-sensitive mechanisms (e.g., Anstis \& Cavanagh, 1981; Mather, Cavanagh, \& Anstis, 1985; but see von Grunau, 1986).

A broader problem in the appeal to neural mechanisms concerns the divergence between physiological studies, which generally investigate individual neurons, and psychophysical studies, presumably stimulating many populations of neurons, particularly if, like induced movement, large areas of the visual field are likely to be involved (Uttal, 1981). The probably complex pattern of neural activity during perception of induced movement may be difficult to appreciate fully during investigation by current microelectrode methods. This would be particularly true if global mechanisms are postulated.

\section{Induced Movement and General Visual Perception of Object Motion}

Three stimuli might provide information for visual perception of object movement (Wallach, 1982, 1985). These are (a) image displacement across the retina; (b) eye movement in tracking a moving object, which can arise because the eye moves relative to the head and because of head and body movement; and (c) configurational change, whereby movement perception is based on the relation in the retinal image. A pure form of the latter may be observed in induced movement.

An analysis of visual perception of object motion is complicated by the fact that the eye is in virtually constant movement even during fixation (Ditchburn, 1955; Verheijen, 1961), so that image displacement can arise from both object movement and eye movement with respect to the stationary environment. A solution to this problem may lie in the possibility that perception of the stationary environment is largely achieved through a matching of eye movement and image displacement (Jeannerod, Kennedy, \& Magnin, 1979; Teuber, 1960; von Holst, 1954): If one extrapolates, perception of a moving object could be explained by a failure in matching eye movement and image displacement (e.g., Wertheim, 1981).

This suggestion requires that image displacement and eye movement can provide adequate information to explain perception of object movement. Relatively high speeds of object movement can lead to image displacement that is correctly attributed to object movement (e.g., Mack, 1970; Wertheim, 1981; Whipple \& Wallach, 1978). This is unlikely, however, at perceivable low speeds of object movement (e.g., Shaffer \& Wallach, 1966). The fact that an afterimage appears to move during eye movement shows that eye movement can be involved in per- 
ception of object movement (Mack \& Bachant, 1969). Other evidence, however, shows that perception of object motion during eye movement can be poor (e.g., Bridgeman \& Stark, 1979; Ditchburn, 1955; Mack \& Herman, 1972, 1973; Sedgwick \& Festinger, 1976; Wallach \& Lewis, 1965; Wallach, O'Leary, \& McMahon, 1982). Doubts concern the scope of tracking eye movement in providing information about object-motion perception (e.g., Festinger \& Easton, 1974; Festinger et al., 1976; Stoper, 1973; Westheimer \& McKee, 1973): A possible alternative role for such eye movements might be in maintaining detailed (foveal) vision on the tracked object (Wallach, 1985; see also Johnstone \& Mark, 1970, 1971, 1973; Robinson, 1977). Regarding the particular case of eye movement during fixation, Barbur (1985) argued that the effects of this on the retinal image might be filtered out, although the efficacy of such filtering may be limited, if one can extrapolate from studies of autokinetic movement (e.g., Pola \& Matin, 1977; Royce et al., 1966).

The above implies that configurational change must by default have some importance in visual perception of object motion, although, of course, it can supply information only about relative movement. Indirect support for such an assertion comes from the importance of configurational change in movement aftereffects-noted in the Aftereffects and Adaptation of Induced Movement section and in other studies (Day \& Strelow, 1971; Strelow \& Day, 1975) — because aftereffects appear to be indicative of fundamental processes in perception (e.g., Frisby, 1979).

Evidence from induced movement and associated aftereffects suggests that relatively small and relatively central areas tend to be seen as moving. Although, as indicated in the Types of Display section and the Possible Distinction Between Induced Movement With and Without Overall Displacement of the Inducing Stimulus section, neither factor is necessary for induced movement in all cases, the fact that so many displays use an arrangement of a large inducing area surrounding a small induced area indicates that these factors are generally important. There appear to be no reports of good induced movement during simultaneous violation of both factors. Other psychophysical evidence, also suggesting that the visual system tends to treat large areas as stationary, shows that conventional movement aftereffects can be feeble or nonexistent with areas of motion stimulation filling much of the visual field (Thalman, 1921; Wohlgemuth, 1911). Suggesting that a relatively central area tends to be seen as moving does not mean it needs to be in central vision. Rather, it needs to be surrounded by other areas, and this can obviously occur far out in peripheral vision. Within limits (e.g., Day et al., 1979), the degree of absolute peripheralness of the inducing stimulus appears relatively unimportant (e.g., Reinhardt-Rutland, 1981). The possible linking of (a) size and spatial frequency and (b) speed of inducing stimulus in some displays (Levi \& Schor, 1984; Schulman, 1981; Adjacency, Spatial Frequency, and Their Interaction With Speed section) could reflect the fact that in normal forward locomotion of humans, visual motion from a stationary environment increases with eccentricity in the observer's visual field.

The reported improvement of induced movement during orthogonal tracking of the induced stimulus (Bacon et al., 1982; Becklen \& Wallach, 1985) may indicate the importance of configurational factors during eye movement. Consistent with this is a report that perception of relative velocity between objects can be good during tracking eye movement (Wertheim \& Niessen, 1986). As suggested earlier, relatively high speed of object movement can lead to image displacement that is correctly identified as object movement, but increasing speed and extent of eye movement can increase the threshold for detecting the object movement (Bridgeman, Hendry, \& Stark, 1975; Wertheim, 1981). Hence, configurational change may become increasingly important with increasing eye movement.

Physiological evidence for supposing that configurational factors are important at early stages of visual analysis comes from studies concerning relative movement (Sensory and Neural Processes section). More specific to problems of motion perception and eye movement, researchers have identified neurons that respond differently to image displacements arising from object movement and saccadic eye movement (Robinson \& Wurtz, 1976; Straschill \& Hoffman, 1970, in monkey and cat superior colliculus) or tracking eye movement (Galletti, Squatrito, Battaglini, \& Maioli, 1983, 1984, in monkey visual cortex). The last group of authors interpreted such findings as evidence for mechanisms able to respond to object movement, irrespective of eye movement. Palka (1969) reported comparable findings for an insect visual system.

Further research might derive from Gibson's $(1966,1968$, 1979) analysis of "ecological" visual sensation. For example, the stationary environment is often filled with objects that are small and have the potential to move. Therefore, if a moving observer perceives a moving object, that movement must be detected against the visual movement of other, perhaps rather similar objects. For a forward-moving observer, the solution to this problem may lie in the visual movements of stationary objects conforming to flow-field principles, by which rate of visual movement is determined by the closeness of the object to the observer and its degree of eccentricity in the observer's visual field. A physically moving object would be characterized by a visual movement that does not correspond to the above. An area for empirical research might lie in investigating induced movement during a complex array of movements in the inducing stimulus.

\section{Conclusions}

In the last section, I outlined some of the broad principles from empirical research. Other points concern the probable distinction between induced movement with and without overall displacement of the inducing stimulus on the basis of a number of differences, for example, in dichoptic effects (Possible Distinction Between Induced Movement With and Without Overall Displacement of the Inducing Stimulus section). There seems to be reason to suppose that a smoothly oscillating inducing stimulus may be more effective than a steadily moving stimulus (see, e.g., Gogel, 1979; Speed Effects section); whether this has anything to do with the acceleration of such a stimulus is not known. In at least some cases of induced movement, the best effects require inducing and induced stimuli to be at the same depth (e.g., Gogel \& MacCracken, 1979; Adjacency, Spatial Frequency, and Their Interaction With Speed section). Choice of response measure for induced movement is rather dependent on the type of display used. For example, if the effect 
is weak and short-lived, then qualitative measures alone may be available. Although many response measures have been used for induced movement, no strong evidence indicates that any measure is better than any other, despite, for example, possible problems in relating perceived movement to perceived displacement in induced stimuli (Response Measures section).

I have not yet commented about comparisons among induced rotation, induced movement in depth, and linear forms of induced movement, particularly that form without overall movement of the inducing stimulus. This is because little in the way of formal evidence is available. Two points can be made: First, aftereffects of induced movement seem less readily elicited with linear induced movement; they required tracking eye movements in the only case reported up to now (Morgan, Ward, \& Brussel, 1976; Aftereffects and Adaptation of Induced Movement section). Second, whereas induced rotation is readily observed during vection (Anstis \& Reinhardt-Rutland, 1976), this is less clearly the case with linear induced movement (Rock et al., 1980; Alteration of the Observer's Perception of Space section). These points might be explained, however, by arguing that more motion-sensitive mechanisms are stimulated by inducing rotation and movement in depth than by linear inducing movement, in which mechanisms responsive to one direction alone are available. Such an argument is consistent with two findings for conventional movement aftereffects. First, conventional movement aftereffects are not reported with a stabilized test stimulus when the adapting movement is linear but are reported when it is centrifugal or centripetal (Moulden, 1975). Second, the reduction of movement aftereffects without a stationary patterned surround is greater with linear adapting movement than with rotatory adapting movement (Day \& Strelow, 1971).

The variety of displays in which induced movement is observed almost certainly argues against explanation of induced movement by any one mechanism. Certain explanations, however, now seem unlikely. There is no evidence for eye movements, whether real (Eye Movements section) or felt (Mack et al., 1985). Explanation in terms of cancellation of two types of eye movement (e.g., Bruell \& Albee, 1955; Post, 1986) is more plausible but restricted to induced movement with an overall direction of inducing movement. It cannot account for qualitative differences between linear induced movement with and without overall displacement of the inducing stimulus. Also, tracking eye movements are probably incompletely registered (Felt and Canceled Eye Movements section). Duncker's (1929/ 1938 ) theory (see that section) can now have no more than descriptive validity in such principles as relative size and enclosure (which are not always true: Types of Display section and Possible Distinction Between Induced Movement With and Without Overall Displacement of the Inducing Stimulus section). The principle of fixation is untenable, and separation of systems has probably been superceded by other factors (Adjacency, Spatial Frequency, and Their Interaction With Speed section).

The involvement of Roelofs's (1935) effect (Brosgole, 1966, 1968 ) is contentious. It cannot be applied to induced movement with no overall direction of inducing movement (e.g., Gogel, 1977) or to induced movement without overall displacement of the inducing stimulus (Bacon et al., 1982). It has been found in cases of induced movement with overall displacement of the inducing stimulus, but that does not mean it causes induced movement (Mack et al., 1985; Alteration of the Observer's Perception of Space section). A subject-relative mechanism, however, could certainly explain a number of differences found between induced movement with and without overall displacement of the inducing stimulus, such as dichoptic effects (Day \& Dickinson, 1977; Possible Distinction Between Induced Movement With and Without Overall Displacement of the Inducing Stimulus section). It is a little unclear what other evidence can be used to resolve this issue. Perhaps a multifactorial experiment investigating correlations between increased induced movement and the presence of displacement in the observer's spatial perception in a wide variety of displays would be useful. No evidence indicates that the analogous rod-and-frame effect contributes to induced rotation and its aftereffect (e.g., Day, 1981).

The possible role of inferential processing, coupled with possible effects of experience, can be shown in induced movement (Farne, 1977; Jensen, 1960; Krolik, 1935), although whether it contributes much to the understanding of induced movement as a whole is doubtful (Induced Movement and "Intelligent" Perception section).

The value of linking induced movement to neural processes is strengthened by simultaneous motion-contrast effects, in which the involvement of neural processes of lateral inhibition appears plausible (e.g., Walker \& Powell, 1974), and by aftereffects of induced movement (e.g., Anstis \& Reinhardt-Rutland, 1976; Sensory and Neural Processes section). Neural properties varying with eccentricity and concerning, for example, receptive-field size (e.g., Humphrey, 1968) and velocity sensitivity (e.g., Orban \& Kennedy, 1981) may be important. A neural explanation may not be appropriate to certain types of induced movement (e.g., Farne, 1977) and to components of induced movement arising from overall displacement of the inducing stimulus. It could be useful in accounting for that component of induced movement with overall displacement of the inducing stimulus that Bacon et al. (1982) suggested is due to configurational factors.

Finally, the observation of induced movement and the associated aftereffect in a wide range of displays argues for the importance of configurational change as a stimulus in the visual perception of object movement. Although configurational change may only signal relative movement of objects, this assertion is supported by the limitations of information from both image displacement and eye movement.

\section{References}

Ames, A. (1951). Visual perception and the rotating trapezoidal window. Psychological Monographs, 65(Whole No. 324).

Anstis, S. M., \& Cavanagh, P. (1981). What goes up need not come down: Moving flicker edges give positive motion aftereffects. In $\mathbf{J}$. Long \& A. Baddeley (Eds.), Attention and performance IX (pp. 6378). Hillsdale, NJ: Erlbaum.

Anstis, S. M., \& Gregory, R. L. (1965). The aftereffect of seen motion: The role of retinal stimulation and eye movements. Quarterly Journal of Experimental Psychology, 17, 173-174.

Anstis, S. M., \& Reinhardt-Rutland, A. H. (1976). Interactions between motion aftereffects and induced movement. Vision Research, 16, 1391-1394. 
Anstis, S. M., Shopland, C. D., \& Gregory, R. L. (1961). Measuring visual constancy for stationary or moving objects. Nature, 191, 416417.

Aschan, G., \& Bergstedt, M. (1955). The genesis of secondary nystagmus induced by vestibular stimuli. Acta Societatis Medicorum Upsaliensis, 60, 1-13.

Bacon, J. H., Gordon, A., \& Schulman, P. H. (1982). The effect of two types of induced-motion displays on perceived lacation of the induced target. Perception and Psychophysics, 32, 353-359.

Barbur, J. L. (1985). Speed discrimination and its relation to involuntary eye movements in human vision. Neuroscience Letters, 54, 712.

Barlow, H. B., \& Hill, R. M. (1963). Evidence for physiological explanation of the waterfall illusion and figural aftereffects. Nature, 200, 1434-1435.

Barlow, H. B., Hill, R. M., \& Levick, W. R. (1964). Retinal ganglion cells responding selectively to direction and speed of image motion in the rabbit. Journal of Physiology, 173, 377-407.

Barlow, H. B., \& Levick, W. R. (1965). The mechanism of directionally selective units in rabbit's retina. Journal of Physiology, 178, 477-504.

Bassili, J. N., \& Farber, J. M. (1977). Experiments on the locus of induced movement. Perception and Psychophysics, 21, 157-161.

Becklen, R., \& Wallach, H. (1985). How does speed change affect induced motion' Perception and Psychophysics, 37, 231-236.

Beverley, K. I., \& Regan, D. (1979). Separable aftereffects of changingsize and motion-in-depth: Different neural mechanisms? Vision Research, 19, 727-732.

Bonnet, C., \& Pouthas, B. (1972). Interactions between spatial and kinetic dimensions in movement aftereffect. Perception and Psychophysics, 12, 193-200.

Bridgeman, B. (1972). Visual receptive fields sensitive to absolute and relative movement during tracking. Science, 178, 1106-1 108.

Bridgeman, B., Hendry, D., \& Stark, L. (1975). Failure to detect displacement of the visual world during saccadic eye movement. Vision Research, 15, 719-722.

Bridgeman, B., Kirch, M., \& Sperling, A. (1981). Segregation of cognitive and motor aspects of visual function using induced motion. Perception and Psychophysics, 29, 336-342.

Bridgeman, B., \& Klassen, H. (1983). On the origin of stroboscopic induced motion. Perception and Psychophysics, 34, 149-154.

Bridgeman, B., \& Stark, L. (1979). Omnidirectional increase in threshold for image shifts during saccadic eye movements. Perception and Psychophysics, 25, 241-243.

Brosgole, L. (1966). An analysis of induced motion (Tech. Rep. No. NAVTRADEVCEN IH-48). Port Washington, NY; U.S. Naval Training Device Center.

Brosgole, L. (1968). An analysis of induced motion. Acta Psychologica, $28,1-44$.

Brosgole, L., Cristal, R. M., \& Carpenter, O. (1968). The role of eye movements in the perception of visually induced motion. Perception and Psychophysics, 3, 166-168.

Brown, J. F. (1931). The visual perception of velocity. Psychologische Forschung, 14, 199-232.

Bruell, J. H., \& Albee, G. W. (1955). Notes towards a motor theory of visual egocentric localization. Psychological Review, 62, 391-400.

Burns, B. D., Gassanov, U., \& Webb, A. C. (1972). Responses of neurones in the cat's visual cerebral cortex to relative movement of patterns. Journal of Physiology, 226, 133-151.

Carr, H. A., \& Hardy, M. C. (1920). Some factors in the perception of relative motion. A preliminary experiment. Psychological Review, 27, 24-37.

Cavanagh, P., \& Favreau, O. E. (1980). Motion aftereffect: A global mechanism for the perception of rotation. Perception, 9, 175-182.

Cleland, B. G., \& Levick, W. R. (1974). Brisk and sluggish concentri- cally organized ganglion cells of the cat's retina. Journal of Physiology, 240, 421-456.

Cohen, R. L. (1965). Adaptation effects and after effects of moving patterns viewed in the periphery of the visual field. Scandinavian Journal of Psychology, 6, 257-264.

Collewijn, H. (1969). Optokinetic eye movements in the rabbit: Inputoutput relations. Vision Research, 9, 117-132.

Coren, S., \& Girgus, J. S. (1978). Seeing is deceiving: The psychology of visual illusions. Hillsdale, NJ: Erlbaum.

Cornsweet, T. N. (1970). Visual perception. New York: Academic Press.

Day, R. H. (1981). Induced rotation with concentric patterns. Perception and Psychophysics, 29, 493-499.

Day, R. H., \& Dickinson, R. G. (1977). Absence of color-selectivity in Duncker-type induced visual movement. Perception and Psychophysics, 22, 313-320.

Day, R. H., Dickinson, R. G., \& Forster, K. I. (1976). Induced subjectrelative movement: Persistence of apparent movement of a stationary point after removal of inducing stimulus. Perception and Psychophysics, 19, 510-517.

Day, R. H., Miller, J., \& Dickinson, R. G. (1979). Induced movement as nonveridical resolution of displacement: Effect of enclosure and number of field elements. Perception and Psychophysics, 25, 23-28.

Day, R. H., \& Strelow, E. (1971). Reduction or disappearance of visual after effect of movement in the absence of patterned surround. $\mathrm{Na}$ ture, 230, 55-56.

Dichgans, J., \& Brandt, T. (1978). Visual-vestibular interaction: Effects of self-motion perception and postural control. In R. Held, H. W. Leibowitz, \& H.-L. Teuber (Eds.), Handbook of sensory physiology, VIII, perception (pp. 755-804). West Berlin, FRG: Springer-Verlag.

Diener, H. C., Wist, E. R., Dichgans, J., \& Brandt, T. (1976). The spatial frequency effect on perceived velocity. Vision Research, 16, 169-176.

Ditchburn, R. (1955). Eye movements in relation to retinal action. Optica Acta, 1, 171-176.

Duncker, K. (1938). Uber induzierte Bewegung (Ein Beitrag zur Theorie optisch wahrgenommener Bewegung) [Concerning induced movement]. In W, D. Ellis (Ed. and Trans.), Source book of Gestalt psychology (pp. 161-172). London: Routledge \& Kegan Paul. (Reprinted from Psychologische Forschung, 1929, 12, 180-259)

Farne, M. (1970). Induced motion in three dimensions. Perceptual and Motor Skills, 30, 426.

Farne, M. (1972). Studies on induced motion in the third dimension. Perception, 1, 351-357.

Farne, M. (1977). Motion in depth induced by brightness changes in the background. Perception, 6, 295-297.

Festinger, L., \& Easton, A. M. (1974). Inferences about the efferent system based on a perceptual illusion produced by eye movements. Psychological Review, 81, 44-58.

Festinger, L., Sedgwick, H. A., \& Holtzman, J. D. (1976). Visual perception during smooth pursuit eye movements. Vision Research, 16, 1377-1386.

Friedlander, M. J., Lin, C. S., Stanford, L. R., \& Sherman, S. M. (1981). Morphology of functionally identified neurons in the lateral geniculate nucleus of the cat. Journal of Neurophysiology, 46, 80-129.

Frisby, J. P. (1979). Seeing. Oxford, England: Oxford University Press.

Frost, B. J., \& Nakayama, K. (1983). Single visual neurons code opposing motion independent of direction. Science, 220, 744-745.

Fukuda, Y., \& Stone, J. (1974). Retinal distribution and central projections of Y-, X-, and W-cells of the cat's retina. Journal of Neurophysiology, 37, 749-772.

Galletti, C., Squatrito, S., Battaglini, P., \& Maioli, M. G. (1983). Nonoriented cells of the striate cortex activated during smooth pursuit eye movements and steady fixations in behaving monkeys. Brain Research, 260, 128-130.

Galletti, C., Squatrito, S., Battaglini, P., \& Maioli, M. G. (1984). 'Real- 
motion' cells in the primary visual cortex of macaque monkeys. Brain Research, 301, 95-110.

Gibson, J. J. (1966). The senses considered as perceptual systems. Boston: Houghton Mifflin.

Gibson, J. J. (1968). What gives rise to the perception of motion? Psychological Review, 75, 335-345.

Gibson, J. J. (1979). The ecological approach to visual perception. Boston: Houghton Mifflin.

Gogel, W. C. (1956). Relative visual direction as a factor in relative distance perceptions. Psychological Monographs: General and Applied, 70(1I, Whole No. 418).

Gogel, W. C. (1975). Depth adjacency and the Ponzo illusion. Perception and Psychophysics, 17, 125-132.

Gogel, W. C. (1977). Independent motion induction in separated portions of the visual field. Bulletin of the Psychonomic Society, 10, 408 410.

Gogel, W. C. (1979). Induced motion as a function of the speed of the inducing object, measured by means of two methods. Perception, 8 , 255-262.

Gogel, W. C., \& Griffin, B. W. (1982). Spatial induction of illusory motion. Perception, 11, 187-199.

Gogel, W. C., \& Koslow, M. (1972). The adjacency principle and induced movement. Perception and Psychophysics, 11, 309-314.

Gogel, W. C., \& MacCracken, P. J. (1979). Depth adjacency and induced motion. Perceptual and Motor Skills, 48, 343-350.

Gogel, W. C., \& Newton, R. E. (1975). Depth adjacency and the rodand-frame illusion. Perception and Psychophysics, 18, 163-171.

Goodenough, D. R., Oltman, P. K., Sigman, E., \& Cox, P. W. (1981). The rod-and-frame illusion in erect and supine observers. Perception and Psychophysics, 29, 365-370.

Gregory, R. L. (1970). The intelligent eye. New York: McGraw-Hill.

Hammond, P., \& MacKay, D. M. (1977). Differential responsiveness of simple and complex cells in cat striate cortex to visual texture. Experimental Brain Research, 30, 275-296.

Hammond, P., \& MacKay, D. M. (1981). Modulatory influences of moving textured backgrounds on responsiveness of single cells in feline striate cortex. Journal of Physiology, 319, 431-442.

Harris, C. S. (1974). Beware of the straight-ahead shift-A nonperceptual change in experiments on adaptation to displaced vision. Perception, 3, 461-476.

Harris, C. S. (1980). Insight or out of sight? Two examples of perceptual plasticity in the human adult. In C. S. Harris (Ed.), Visual coding and adapability (pp. 95-149). Hillsdale, NJ: Erlbaum.

Held, R., Dichgans, J., \& Bauer, J. (1975). Characteristics of moving scenes influencing spatial orientation. Vision Research, 15, 357-365.

Helmholtz, H. von. (1967). Treatise on physiological optics, Volumes I and 2 (J. P. C. Southall, Trans.). New York: Dover. (Original work published 1925)

Henn, V., Cohen, B., \& Young, L. R. (1980). Visual-vestibular interaction in motion perception and the generation of nystagmus. Neurosciences Research Program Bulletin, 18, 459-651.

Hershberger, W., Laughlin, N., \& Nitschke, W. (1976). A dynamic Ponzo illusion: Induced direction of rotation in depth. Perception, 5, 197-202.

Hershenson, M. (1984). Phantom spiral aftereffect: Evidence for global mechanisms in perception. Bulletin of the Psychonomic Society, 22, 535-537.

Hoffman, K. P. (1973). Conduction velocity in pathways from retina to superior colliculus in the cat: A correlation with receptive field properties. Journal of Neurophysiolog, 436, 409-424.

Hoffman, K. P., Stone, J., \& Sherman, S. M. (1972). Relay of receptive field properties in dorsal lateral geniculate nucleus of the cat. Journal of Neurophysiology, 35, 518-531.

Holmgren, S. (1974). On searching for Mach band type phenomena in the visual perception of spatial velocity distributions (Report 151). East Orange, NJ: University of Upsala, Department of Psychology.

Howard, I. P. (1966). Human spatial orientation. London: Wiley.

Hughes, P. C. (1972). The influence of the visual field upon the visual vertical in relation to ocular torsion of the eye. (Doctoral thesis, University of Oklama, 1972). Dissertation Abstracts International, 33, 4686B.

Humphrey, N. K. (1968). Responses to visual stimuli of units in the superior colliculus of rats and monkeys. Experimental Neurology, 20, 312-340.

Hunzelman, N., \& Spillman, L. (1984). Movement adaptation in the peripheral retina. Vision Research, 12, 1765-1769.

Ittelson, W. H. (1951). Size as a cue to distance: Radial motion. American Journal of Psychology, 64, 188-202.

Ittelson, W. H., \& Kilpatrick, F. P. (1951). Experiments in perception. Scientific American, 185, 50-55.

Jeannerod, M., Kennedy, H., \& Magnin, M. (1979). Corollary discharge: Its possible implications in visual and oculomotor interactions. Neuropsychologia, 17, 241-258.

Jensen, G. D. (1960). Effect of past experience on induced movement. Perceptual and Motor Skills, 11, 281-288.

Johnstone, J. R., \& Mark, R. F. (1970). Two classes of eye movement and their perceptual consequences. Proceedings of the Australian Physiological and Pharmacological Society, 1, 46-47.

Johnstone, J. R., \& Mark, R. F. (1971). The efference copy neurone. Journal of Experimental Biology, 54, 403-414.

Johnstone, J. R., \& Mark, R. F. (1973). Corollary discharge. Vision Research, 13, 1621.

Kohler, W. (1947). Gestalt psychology. New York: Mentor.

Krolik, W. (1935). Uber Erfahrungwirkungen beim Bewegungssehen [Concerning the effects of experience on seeing movement]. Psychologische Forschung, 20, 47-101.

Leventhal, A. G. (1982). Morphology and distribution of retinal ganglion cells projecting to different layers of the dorsal lateral geniculate nucleus in normal and Siamese cats. Journal of Neuroscience, 2, 1024-1042.

Levi, D. M., \& Schor, C. M. (1984). Spatial and velocity tuning of processes underlying induced motion. Vision Research, 24, 1189-1196.

Loomis, J. M., \& Nakayama, K. (1973). A velocity analogue of brightness contrast. Perception, 2, 425-428.

Mack, A. (1970). An investigation of the relationship between eye and retinal image movement in the perception of movement. Perception and Psychophysics, 8, 291-298.

Mack, A., \& Bachant, J. (1969). Perceived movement of the afterimage during eye movements. Perception and Psychophysics, 6, 379-384.

Mack, A., Fisher, C. B., \& Fendrich, R. (1975). A reexamination of twopoint induced movement. Perception and Psychophysics, 17, 273276.

Mack, A., \& Herman, E. (1972). A new illusion: The underestimation of distance during smooth pursuit eye movements. Perception and Psychophysics, 12, 471-473.

Mack, A., \& Herman, E. (1973). Position constancy during pursuit eye movement: An investigation of the Filehne illusion. Quarterly Journal of Experimental Psychology, 25, 71-84.

Mack, A., Heuer, F., Fendrich, R., Vilardi, K., \& Chambers, D. (1985). Induced motion and oculomotor capture. Journal of Experimental Psychology: Human Perception and Performance, 11, 329-345.

Mandl, G. (1970). Localization of visual patterns by neurons in cerebral cortex of cat. Journal of Neurophysiology, 33, 812-826.

Mandl, G. (1974). The influence of visual pattern combinations on responses of movement sensitive cells in the cat's superior colliculus. Brain Research, 75, 215-240.

Mather, G. (1980). The movement aftereffect and a distribution-shift 
model for coding the direction of visual movement. Perception, 9 , 379-392.

Mather, G., Cavanagh, P., \& Anstis, S. M. (1985). A moving display which opposes short-range and long-range signals. Perception, 14, 163-166.

McColgin, F. H. (1960). Movement thresholds in peripheral vision. Journal of the Optical Society of America, 50, 774-779.

McConkie, A. B., \& Farber, J. M. (1979). Relation between perceived depth and perceived motion in uniform flow fields. Journal of Experimental Psychology: Human Perception and Performance, 6, 391-403.

Morgan, M. J. (Speaker). (1984). Visual inference. (Audiocassette recording, Tape 7: Prog: 122-84). London: Audio-Bass, in conjunction with the British Psychological Society.

Morgan, M. J., Ward, R. M., \& Brussell, E. M. (1976). The aftereffect of tracking eye movements. Perception, 5, 309-317.

Moulden, B. (1975). Eye movements and the movement aftereffect. $\mathrm{Vi}$ sion Research, 15, 1169-1170.

Nakayama, K., \& Tyler, C. W. (1978). Relative motion induced between stationary lines. Vision Research, 18, 1663-1668.

Oatley, K. (1978). Perception and representations. New York: Free Press.

Oppenheimer, E. (1935). Optische Versuche ueber Ruhe und Bewegung [Optical experiments concerning stationarity and movement]. Psychologische Forschung, 20, 1-46.

Orban, G. A., Duysens, J., \& van der Glas, H. W. (1980). Neuronal properties in Area 19 of the cat. Society for Neuroscience Abstracts, 6,579 .

Orban, G. A., \& Kennedy, H. (1981). The influence of eccentricity on receptive field types and orientation selectivity in Areas 17 and 18 of the cat. Brain Research, 208, 203-208.

Orban, G. A., Kennedy, H., \& Maes, H. (1981). Velocity sensitivity of Areas 17 and 18 of the cat. Acta Psychologica, 48, 303-309.

Over, R., \& Lovegrove, W. (1973). Color-selectivity in simultaneous motion contrast. Perception and Psychophysics, 14, 445-448.

Palka, J. (1969). Discrimination between movements of eye and object by visual interneurones of crickets. Journal of Experimental Biology, 50, 723-732.

Pantle, A. (1974). Motion aftereffect magnitude as a measure of the spatio-temporal response properties of direction-sensitive analyzers. Vision Research, 14, 1229-1236.

Pola, J., \& Matin, L. (1977). Eye movements following autokinesis. Bulletin of the Psychonomic Society, 10, 397-398.

Post, R. B. (1986). Induced motion considered as a visually induced oculogyral illusion. Perception, 15, 131-138.

Post, R. B., \& Heckman, T. (1986). Induced motion and apparent straight ahead during prolonged stimulation. Perception and Psychophysics, 40, 263-270.

Post, R. B., \& Leibowitz, H. W. (1985). A revised analysis of the role of efference in motion perception. Perception, 14, 631-643.

Post, R. B., Schupert, C. L., \& Leibowitz, H. W. (1984). Implications of OKN suppression by smooth pursuit for induced motion. Perception and Psychophysics, 36, 493-498.

Ratliff, F. (1965). Mach bands: Quantitative studies on neural networks in the retina. New York: Holden-Day.

Regan, D. (1986). Visual processing of four kinds of relative motion. Vision Research, 26, 127-145.

Reinhardt-Rutland, A. H. (1981). Peripheral movement, induced movement, and aftereffects of induced movement. Perception, 10 , 173-182.

Reinhardt-Rutland, A. H. (1983a). Aftereffect of induced rotation: Number of radial lines in inducing stimulus. Perceptual and Motor Skills, 57, 39-42.

Reinhardt-Rutland, A. H. (1983b). Aftereffect of induced rotation: Separation of inducing and static areas, and monocular component. Perceptual and Motor Skills, 56, 239-242.
Reinhardt-Rutland, A. H. (1983c). Induced movement-in-depth: Relative location of static stimulus and direction asymmetry. Perceptual and Motor Skills, 57, 255-258.

Reinhardt-Rutland, A. H. (1984). Negative aftereffect arising from prolonged viewing of induced movement-in-depth. Perceptual and Motor Skills, 58, 359-362.

Reinhardt-Rutland, A. H. (1985). A new visual factor in certain driving problems. In D. J. Oborne (Ed.), Contemporary ergonomics, 1985 (pp. 60-69). London: Taylor and Francis.

Richards, W. (1971). Motion detection in man and other animals. Brain, Behavior and Evolution, 4, 162-181.

Rizzolatti, G., \& Camarda, R. (1975). Inhibition of visual responses of single units in the cat visual area of the lateral suprasylvian gyrus by introduction of a second visual stimulus. Brain Research, 88, 357361.

Rizzolatti, G., \& Camarda, R. (1977). Influence of the presentation of remote visual stimuli on visual responses of Cat Area 17 and lateral suprasylvian area. Experimental Brain Research, 29, 107-122.

Rizzolatti, G., \& Camarda, R., Grupp, L. A., \& Pisa, M. (1974). Inhibitory effect of remote visual stimuli on the visual responses of the cat superior colliculus: Spatial and temporal factors. Journal of Neurophysiology, 37, 1262-1275.

Robinson, D. (1977). Vestibular and optokinetic symbiosis: An example of explaining by modelling. In R. Baker \& A. Berthoz (Eds.), Control of gaze by brain stem neurons (pp. 49-58). Amsterdam: Elsevier.

Robinson, D. L., \& Wurtz, R. H. (1976). Use of an extraretinal signal by monkey superior colliculus neurons to distinguish real from selfinduced stimulus movement. Journal of Neurophysiology, 39, 852870.

Robinson, J. O. (1972). The psychology of visual illusion. London: Hutchinson.

Rock, I. (1983). The logic of perception. Cambridge, MA: MIT Press.

Rock, I., Auster, M., Schiffman, M., \& Wheeler, D. (1980). Induced movement based on subtraction of motion from the inducing object. Journal of Experimental Psychology: Human Perception and Performance, 6, 391-403.

Roelofs, C. O. (1935). Optische Lokalisation [Optical localization]. Archiv fur Augenheilkunde, 109, 395-415.

Ross, H. E. (1974). Behaviour and perception in strange environments. London: Allen and Unwin.

Royce, J. R., Carran, A. B., Aftanas, M., Lehman, R. S., \& Blumenthal, A. (1966). The autokinesis phenomenon. Psychological Bulletin, 65 . 243-260.

Schulman, P. H. (1979). Eye movements do not cause induced motion. Perception and Psychophysics, 26, 381-383.

Schulman, P. H. (1981). Antagonistic effects of adjacency and apparent speed in induced movement. Journal of Experimental Psychology: Human Perception and Performance, 7, 985-994.

Sedgwick, H. A., \& Festinger, L. (1976). Eye movements, efference and visual perception. In R. A. Monty \& J. W. Senders (Eds.), Eye movements and psychological processes (pp. 221-230). Hillsdale, NJ: Erlbaum.

Sekuler, R., \& Ganz, L. (1963). Aftereffect of seen motion with a stabilized retinal image. Science, 139, 419-420.

Shaffer, O., \& Wallach, H. (1966). Extent-of-motion thresholds under subject-relative and object-relative conditions. Perception and Psychophysics, 1, 447-451.

Sherman, S. M. (1985). Functional organization of the $W_{m}, X_{-}$, and $Y_{-}$ cell pathways in the cat: A review and hypothesis. In J. M. Sprague \& A. N. Epstein (Eds.), Progress in psychobiology and physiological psychology (Vol. 11, pp. 233-314). New York: Academic Press.

Smith, A. T., \& Over, R. (1979). Motion aftereffect with subjective contours. Perception and Psychophysics, 25, 93-98.

Sprague, J. M., Marchiafava, P. L., \& Rizzolatti, G. (1968). Unit re- 
sponses to visual stimuli in the superior colliculus of the unanesthetized, mid-pontine cat. Archives Italiennes de Biologie, 106, 169193.

Srinavason, M. V., \& Dvorak, D. R. (1979). The waterfall illusion in an insect visual system. Vision Research, 19, 1435-1438.

Sterling, P., \& Wickelgren, B. G. (1969). Visual receptive fields in the superior colliculus of the cat. Journal of Neurophysiology, 32, 1-15.

Stoper, A. E. (1973). Apparent motion of stimuli presented stroboscopically during smooth pursuit movement of the eye. Perception and Psychophysics, 13, 201-211.

Straschill, M., \& Hoffman, K. P. (1970). Activity of movement sensitive neurons of the cat's tectum opticum during spontaneous eye movements. Experimental Brain Research, 11, 318-326.

Strelow, E. R., \& Day, R. H. (1975). Visual movement aftereffect: Evidence for independent adaptation to moving target and stationary surround. Vision Research, 15, 117-121.

Sugarman, R. C., \& Cohen, W. (1968). Perceived target displacement as a function of field movement and asymmetry. Perception and Psychophysics, 3, 169-173.

Sutherland, N. S. (1961). Figural aftereffects and apparent size. Quarterly Journal of Psychology, 13, 222-228.

Swanston, M. T., \& Wade, N. J. (1983). Binocular interaction in induced movement. Perception. 12, A16.

Taylor, M. M. (1963). Tracking the neutralization of seen rotary movement. Perceptual and Motor Skills, 16, 513-519.

Teuber, H. L. (1960). Perception. In J. Field, H. W. Magoun, \& E. V. Hall (Eds.), Handbook of physiology: Neurophysiology III (pp. 15951688). Baltimore, MD: Williams \& Wilkins.

Thalman, W. A. (1921). The after-effect of seen movement when the whole visual field is filled by a moving stimulus. American Journal of Psychology, 32, 429-441.

Thelin, E. (1927). Perception of relative visual motion. Journal of Experimental Psychology, 10, 321-349.

Tynan, P., \& Sekuler, R. (1975). Simultaneous motion contrast: Velocity sensitivity and depth response. Vision Research, 15, 1231-1238.

Uttal, W. R. (1981). A taxonomy of visual processes. Hillsdale, NJ: Erlbaum.

van Waters, R. O. (1934). Visual perception of horizontal movement. Journal of Experimental Psychology, 17, 223-245.

Vautin, R. G., \& Berkley, M. A. (1977). Responses of single cells in cat visual cortex to prolonged stimulus movement: Neural correlates of visual aftereffects. Journal of Neurophysiology, 40, 1051-1065.

Verheijen, F. J. (1961). A simple after image method demonstrating the involuntary multi-directional eye movements during fixation. Optical Acta, 8, 309-311.

von Grunau, M. W. (1986). A motion aftereffect for long-range stroboscopic apparent motion. Perception and Psychophysics, 40, 31-38.

von Holst, E. (1954). Relationships between the central nervous system and the peripheral organs. British Journal of Animal Behaviour, 2, 89-94.
Wade, N. J., \& Swanston, M. T. (1984). Illusions of size change in dynamic displays. Perception and Psychophysics, 35, 286-290.

Wagenaar, W. A., Frankenhuizen, J., Vos, J., \& Flores d'Arcais, G. B. (1984). There is no induced motion at near-threshold velocities. Acta Psychologica, 55, 295-313.

Walker, P., \& Powell, D. J. (1974). Lateral interaction between neural channels sensitive to velocity in human visual system. Nature, 252, 732-733.

Wallach, H. (1959). Perception of motion. Scientific American, 201, 56-60.

Wallach, H. (1982). Eye movement and motion perception. In A. H. Wertheim, W. A. Wagenaar, \& H. W. Leibowitz (Eds.), Tutorials in motion perception (pp. 1-18). New York: Plenum Press.

Wallach, H. (1985). Learned stimulation in space and motion perception. American Psychologist, 40, 399-404.

Wallach, H., Bacon, J., \& Schulman, P. (1978). Adaptation in motion perception: Alteration of induced motion. Perception and Psychophysics, 24, 509-514.

Wallach, H., \& Becklen, R. (1983). An effect of speed on induced motion. Perception and Psychophysics, 34, 237-242.

Wallach, H., \& Lewis, C. (1965). The effect of abnormal displacement of the retinal image during eye movements. Perception and Psychophysics, 1, 25-29.

Wallach, H., O'Leary, A., \& McMahon, M. L. (1982). Three stimuli for visual motion perception compared. Perception and Psychophysics, $32,1-6$.

Weisstein, N., Maguire, W., \& Berbaum, K. (1977). A phantom-motion aftereffect. Science, 198, 955-958.

Wertheim, A. H. (1981). On the relativity of perceived motion. Acta Psychologica, 48, 97-110.

Wertheim, A. H., \& Niessen, M. W. (1986). The perception of relative motion between objects during pursuit eye movement. Perception, 15 , A9.

Westheimer, G., \& McKee, S. P. (1973). Failure of Donders' law during smooth pursuit eye movements. Vision Research, 13, 2145-2153.

Whipple, W. R., \& Wallach, H. (1978). Direction-specific motion thresholds for abnormal image shifts during eye movement. Perception and Psychophysics, 24, 349-355.

Witkin, H. A., Dyk, R. B., Faterson, H. F., Goodenough, D. R., \& Karp, S. A. (1974). Psychological differentation. Potomac, MD: Erlbaum. (Original work published 1962)

Wohlgemuth, A. (1911). On the after effect of seen movement. British Joumal of Psychology (Monograph Suppl. 1).

Received July 16,1986

Revision received December 29, 1986

Accepted April 8, 1987

\section{Correction to Marks and Miller}

In the article "Ten Years of Research on the False-Consensus Effect: An Empirical and Theoretical Review," by Gary Marks and Norman Miller (Psychological Bulletin, 1987, Vol. 102, No. 1, pp. 72-90), the block quotation on page 73 should be attributed to Crocker (1981). The two sentences immediately preceding this quotation should read: "Friendship groups typically exhibit a high degree of internal similarity with respect to members' beliefs, attitudes, values, and interests. Crocker (1981) reported the following:" 